\title{
PROJETO ESCOLA INTERCULTURAL BILÍNGUE DE FRONTEIRA: UMA METANÁLISE DAS CONCEPÇÕES DE BILINGUISMO E EDUCAÇÃO BILÍNGUE
}

\author{
PROYECTO ESCUELA INTERCULTURAL BILÍNGÜE DE FRONTERA: UNA META \\ ANÁLISIS DE LAS CONCEPCIONES DE BILINGÜUSMO Y EDUCACIÓN BILÍNGÜE
}

\section{THE BILINGUAL INTERCULTURAL FRONTIER SCHOOL PROJECT: A META- ANALYSIS OF THE CONCEPTIONS OF BILINGUALISM AND BILINGUAL EDUCATION}

\author{
Isabela Vieira BARBOSA ${ }^{1}$ \\ Cleide Beatriz Tambosi PISETTA ${ }^{2}$
}

RESUMO: No Brasil, em geral, há uma crença no mito do monolinguismo a partir do qual se acredita na predominância e soberania única do português em território brasileiro. O propósito deste trabalho é discutir resultados parciais de uma pesquisa sobre concepções de bilinguismo e educação bilíngue adotadas por pesquisadores em produções científicas relacionadas às áreas de Educação e Linguagem. Desta forma, busca-se abordadas análises com relação ao PEIBF Projeto Escola Intercultural Bilíngue de Fronteira realizado por países membros do Mercosul. O levantamento de dados foi feito na ANPED - Associação Nacional de Pós-Graduação e Pesquisa em Educação - e na BDTD - Banco Nacional de Teses e Dissertações - entre os anos de 2010 e 2015, e utilizou como base questões sobre bilinguismo e educação bilíngue. O objetivo é mapear as concepções utilizadas nas pesquisas sobre bilinguismo e educação bilíngue e os acordos teóricos que embasam tais concepções. A importância desta pesquisa ocorre diante da carência de conhecimentos sobre o PEIBF e concepções utilizadas neste programa. Além de proporcionar um melhor entendimento dos métodos e teorias dominantes na área. Nossos dados apontam que as pesquisas realizadas dentro de um contexto de fronteira, se direcionam para uma visão sociofuncional. Nesta compreensão, o bilinguismo e a educação bilíngue são entendidos não apenas como o ensino e o domínio de uma habilidade linguística, mas como um fenômeno social que ocorre dentro de um contexto sócio-histórico especifico. No caso da fronteira, as concepções são construídas através do contato entre dois países, duas culturas e duas línguas.

PALAVRAS-CHAVE: PEIBF. Concepções de bilinguismo e Educação Bilíngue. Línguas de fronteira.

RESUMEN: En Brasil, en general, hay una creencia en el mito del monolingüismo de la que se cree en la prevalencia y la soberanía única de los portugueses en Brasil. El propósito de este trabajo es discutir resultados parciales de una investigación sobre concepciones de bilingüismo y educación bilingüe adoptadas por investigadores en producciones científicas relacionadas a las áreas de Educación y Lenguaje. De esta forma, se buscan abordados

1 Escola Barão do Rio Branco, Blumenau - SC, Brasil. Professora de Língua Inglesa - EFI. ORCID <https://orcid.org/0000-0003-1939-572X>.E-mail: miss.vieira@gmail.com

${ }^{2}$ Colégio São Paulo (CSP), Ascurra - SC, Brasil. Professora de Língua Inglesa e Língua Portuguesa - EFII e EM. ORCID < https://orcid.org/0000-0003-0571-2130>. E-mail: cleybeatriz@ hotmail.com 
análisis con relación al PEIBF - Proyecto Escuela Intercultural Bilingüe de Frontera realizado por países miembros del Mercosur. El análisis de datos fue realizado en la ANPED Asociación Nacional de Postgrado e Investigación en Educación - y en la BDTD - Banco Nacional de Tesis y Disertaciones - entre los años 2010 y 2015 que utilizó como base cuestiones sobre bilingüismo y educación bilingüe. El objetivo es mapear las concepciones utilizadas en las investigaciones sobre bilingüismo y educación bilingüe y los acuerdos teóricos que fundamentan tales concepciones. La importancia de esta investigación ocurre antela carencia de conocimientos sobre el PEIBF y concepciones utilizadas en este programa. Además de proporcionar un mejor entendimiento de los métodos y teorías dominantes en el área. Nuestros datos apuntan que las investigaciones realizadas dentro de un contexto de frontera, se dirigen hacia una visión sociofuncional. En esta comprensión, el bilingüismo y la educación bilingüe son entendidos no sólo como la enseñanza y el dominio de una habilidad lingüística, sino como un fenómeno social que ocurre dentro de un contexto socio-histórico específico. En el caso de la frontera, las concepciones se construyen a través del contacto entre dos países, das culturas $y$ dos lenguas.

PALABRAS CLAVE: PEIBF. Concepciones de bilingüismo y Educación Bilingüe. Lenguas de frontera.

ABSTRACT: In Brazil, in general, there is a belief in the myth of monolingualism that is believed in the prevalence and the sovereignty of the Portuguese language in Brazilian territory. The purpose of this paper is to discuss partial results of a research on bilingualism and bilingual education conceptions adopted by researchers in scientific productions related to the areas of Education and Language. In this way, we seek to address this analysis in relation to the Intercultural Bilingual School Project (PEIBF) carried out by member countries of Mercosul. The data collection was carried out in the ANPED - a National Association of Postgraduate and Research in Education - and in the BDTD - a Brazilian Digital Library of Theses and Dissertations - between the years 2010 and 2015, using as a base question about bilingualism and bilingual education. The objective is to map the conceptions used in research on bilingualism and bilingual education and the theoretical agreements that support such conceptions. The importance of this research is given the lack of knowledge about the PEIBF and the conceptions used in this program. In addition, this article provides a better understanding of the dominant methods and theories in the area. Our data point out that research carried out within a border context is directed towards a sociofunctional view. In this understanding, bilingualism and bilingual education are understood not only as the teaching and mastery of a linguistic ability, but as a social phenomenon that occurs within a specific socio-historical context. In the case of the frontier, conceptions are constructed through contact between two countries, two cultures and two languages.

KEYWORDS: PEIBF. Conceptions of bilingualism and Bilingual Education. Frontier languages. 


\section{Introdução}

O presente artigo tem o intuito de discutir resultados parciais de uma pesquisa sobre as concepções de bilinguismo e educação bilíngue em pesquisas relacionadas à área da Educação e Linguagem. A partir disso, buscamos apresentar algumas das concepções encontradas nas pesquisas sobre o bilinguismo e a educação bilíngue relacionadas ao PEIBF - Projeto Escola Intercultural Bilíngue de Fronteira realizado por países membros do Mercosul, um programa institucional que visa promover o intercâmbio entre professores dos países do Mercosul (ARGENTINA; BRASIL, 2008).

Para realização desta pesquisa, foi feito um levantamento na base de dados da ANPED - Associação Nacional de Pós-Graduação e Pesquisa em Educação - e na BDTD - Biblioteca Digital Brasileira de Teses e Dissertações - em busca de teses, dissertações e artigos publicados entre os anos de 2010 e 2015 que discutissem os conceitos de bilinguismo e educação bilíngue.

O objetivo desta investigação, bem como da pesquisa maior, é mapear as concepções utilizadas nas pesquisas sobre bilinguismo e educação bilíngue e os acordos teóricos que embasam tais concepções. Diante da carência de conhecimentos sobre o PEIBF e as concepções utilizadas neste programa, buscamos aprofundar um melhor entendimento dos métodos e teorias dominantes na área.

No âmbito da educação, a compreensão desses diferentes cenários culturais possibilita ampliar as discussões na formação do professor, dos pós-graduandos, dos docentes da educação básica e de ensino superior que atuam nestes mesmos contextos socioculturalmente complexos, possibilitando que respeitem as heterogeneidades e desenvolvam práticas transculturais e multilíngues.

Este artigo apresenta um recorte dessa pesquisa, defendida em 2017 num Programa de Pós-Graduação em Educação de uma universidade de Santa Catarina. A presente pesquisa apresenta os acordos teóricos, os contextos de fronteira, os dados analisados, e por fim, as considerações finais.

\section{Acordos teóricos}

Ao discorrermos sobre as línguas de fronteira, abordamos também o contato linguístico que ocorre entre diferentes culturas, muitas vezes levando a uma polarização ou inferiorização de uma dessas culturas. "Desde que os contatos entre os povos de línguas diferentes se estabeleceram, tivemos como consequência uma língua mais importante ou influente [...]" 
(ALVAREZ, 2009, p. 24). O autor justifica que isso ocorria porque a "nação que empregava a língua 'importante' era a potência econômica, política ou cultural do momento" (ALVAREZ, 2009, p. 24 - grifos do autor).

Todas as línguas de alguma forma são influenciadas pelo contato que possuem com as outras. Ao existir uma proximidade geográfica, as chances de uma influência se tornam ainda maiores. $\mathrm{O}$ fato de esses idiomas possuírem origens semelhantes, ou a existência de contatos e acordos político-econômicos entre os países, exercem interferências no terreno linguístico (STURZA, 2006).

Quanto ao contexto geográfico, nem sempre as demarcações territoriais se fazem presentes no âmbito social. Independente dos limites territoriais notou-se ao longo da história que populações não mudam socialmente tal como as fronteiras físicas. Muitas vezes elas se mantêm presas às suas origens culturais, levando-nos assim a crer que as fronteiras são um espaço real e social, que não devem ser vistos como "periferia da nação, como um lugar de término, mas sim como um espaço com sociologia própria, marcado por confluências, tanto integradoras quanto conflitivas" (WEBER, 2011, p. 219).

Assim, em concordância com Weber (2011) destacamos que a fronteira é um lugar de sociologia e cultura peculiar, influenciada pelas diferentes origens e realidades. Geradora de conflitos e integrações, mas de características próprias que a distinguem das demais áreas dos países as quais delimita, criando um contexto tipicamente de convergência.

A circulação do espanhol e do português nas fronteiras brasileiras estabeleceu-se tanto de forma divergente, em virtude das guerras e conflitos, quanto de formas integradoras, como nas atividades do comércio. É necessário destacarmos também que essas regiões de fronteira são muitas vezes motivo de preocupação dos Estados, devido às necessidades de controle sobre os comércios, as legislações etc., “já que, ser fronteira é também ser limite, e, por isso, é remetida a elas a ideia de que conformam um espaço do nada, do confim, do tudo é possível" (ALVAREZ, 2009, p. 25).

Entretanto, conforme Alvarez (2009) ressalta, a fronteira não é um muro de defesa, ou um simples espaço de trânsito entre dois lugares diferentes. A fronteira é um local de diálogo, de trocas culturais, de intercâmbio. E ao levarmos o conceito físico de fronteira para o campo linguístico, resulta "pensar também nas práticas e diversidade culturais geradas nesses espaços" (ALVAREZ, 2009, p. 26).

No Brasil, entretanto, há uma crença no mito do monolinguismo (BORTONIRICARDO, 1984; CAVALCANTI，1999，2011; CAVALCANTI; BORTONI-RICARDO, 2007), da soberania da língua portuguesa em território brasileiro. Porém, Cavalcanti (1999) 
destaca que esse mito serve apenas para favorecer e tentar apagar "as nações indígenas, as comunidades imigrantes e, por extensão, as maiorias tratadas como minorias, ou seja, as comunidades falantes de variedades desprestigiadas do português" (CAVALCANTI, 1999, p. 387).

Neste trabalho, no entanto, compreendemos a região fronteiriça como "configuração de sujeitos, culturas, práticas sociais e culturais" (ALVAREZ, 2009, p. 26), utilizando muitas vezes de uma linguagem própria que transita entre os idiomas das duas regiões abraçadas. No caso do Brasil-Uruguai, Brasil-Paraguai, ou Brasil-Argentina, por exemplo, temos o portunhol. Considerado como a prática de uma mistura gramatical das línguas, (STURZA, 2005, p.49) o portunhol, é considerada uma interlíngua, pois remete a uma situação intermediária, onde há uma mistura tanto em nível gramatical quanto discursivo das línguas (STURZA, 2005). Entretanto, essa interlíngua preza principalmente por essa relação entre os sujeitos fronteiriços, e a forma como fazem as línguas funcionarem, em que "formas são tomadas de empréstimo; sentidos de uma língua são apropriados pela outra língua e novos dizeres se constituem" (STURZA, 2006, p. 68).

\section{Os contextos de fronteira}

Como apresentado no capítulo teórico, a fronteira apresenta como sua principal singularidade o contato geográfico entre dois povos, duas culturas, e muitas vezes também entre duas ou mais línguas. Em tantos momentos vistos como lugares de segurança, de início e fim, nada mais são do que um ambiente de contato entre sujeitos e culturas que se cruzam e se misturam (STURZA, 2005). O contato linguístico que se realiza nesses locais não está envolto com rupturas como os de imigração, não ocorrem com a transposição ou afastamento de sua terra e suas raízes, é um contato que se dá no dia a dia, onde há uma troca e um retorno, muitas vezes sequer notado.

Em um país geograficamente extenso como o Brasil, as fronteiras se apresentam através de inúmeras possibilidades com distintos países. Entre as nações que possuem contato fronteiriço com o Brasil, estão: Argentina, Bolívia, Colômbia, Guiana, Guiana Francesa, Paraguai, Peru, Suriname, Uruguai e Venezuela.

Apesar de nem todos os países limítrofes ao Brasil falarem espanhol, em países como Bolívia, Argentina, Paraguai, Peru e Colômbia, o espanhol é tido como língua oficial, enquanto 
na Guiana ${ }^{3}$ e no Uruguai ${ }^{4}$ o idioma é reconhecido em nível nacional apensar de não ter o status de língua oficial. Talvez por essa maior incidência do idioma hispânico, encontramos 16 pesquisas, que abordam a língua espanhola.

Desses 16 trabalhos, 11 abordam a língua espanhola no contexto de fronteira, enquanto 5 pesquisas (BUENO, 2013; CÁCERES, 2012; CARDOSO, 2015; LIMA, 2011; STEIN, 2014) abordam o ensino do espanhol fora do contexto fronteiriço.

Entre as 11 pesquisas que situam o indivíduo bilíngue na região de fronteira, cabe destacar que, como anteriormente citado, apesar de nem todos os países vizinhos do Brasil serem hispanofalantes, a língua espanhola é a única que se faz presente como podemos perceber no quadro 1.

Quadro 1 - Contexto sócio-histórico das pesquisas do espanhol como línguas de fronteira

\begin{tabular}{|c|c|c|c|}
\hline Autor & Ano & Tipo de trabalho & Local investigado \\
\hline BRAZ, E. & 2010 & Dissertação & Pacaraima/RR \\
\hline CITOLIN, C. & 2013 & Tese & Santana do Livramento/RS \\
\hline COUTO, R. & 2013 & Artigo & Jaguarão/RS \\
\hline FLORES, O. & 2011 & Dissertação & Foz do Iguaçu/PR \\
\hline GONÇALVES, D. & 2013 & Dissertação & Jaguarão/RS \\
\hline NOBRE, W. & 2011 & Dissertação & Revisão bibliográfica \\
\hline OLIVEIRA, R. & 2011 & Dissertação & Foz do Iguaçu/PR \\
\hline PEREIRA, S. & 2014 & Dissertação & Dionísio Cerqueira/SC \\
\hline PREUSS, E. & 2011 & Tese & Santana do Livramento/RS \\
\hline SAGAZ, M. & 2013 & Dissertação & Dionísio Cerqueira/SC \\
\hline VILELA, L. & 2013 & Dissertação & Revisão bibliográfica \\
\hline
\end{tabular}

Fonte: Elaborado pelas pesquisadoras.

O quadro supra apresentado (1) indica que a língua espanhola peninsular ${ }^{5}$ foi pesquisada na totalidade dos trabalhos encontrados e analisados no corpus desta pesquisa, não representando a pluralidade fronteiriça do Brasil. Línguas como o castelhano, o guarani, o francês e o holandês, tidos como idiomas oficias de países vizinhos, não apareceram nas pesquisas aqui destacadas.

A ausência de pesquisas com estas línguas oficias que compõem a fronteira brasileira nos leva a questionar de que forma as relações de poder, sejam elas políticos ou comerciais, atuam na maior valorização de línguas estrangeiras ou não. A ausência do castelhano e do

${ }^{3} \mathrm{O}$ espanhol é amplamente ensinado como segunda língua, utilizado pelos visitantes na região de fronteira com a Venezuela, além de utilizado por uma minoria da população como segunda língua.

${ }^{4}$ Conforme a Ley General de Educación (Lei n. 18.437), não há no Uruguai uma língua oficial. O espanhol uruguaio é tido como língua materna, tal como o português uruguaio e a língua de sinais uruguaia.

${ }^{5}$ Por espanhol peninsular compreendemos neste trabalho como à variante do espanhol utilizado na Espanha. 
guarani, destoam especialmente em virtude dos países de origem, Argentina e Paraguai respectivamente, serem países de grande proximidade social, cultural e política do Brasil.

Tal representação da soberania do espanhol pode justificar-se, talvez, em virtude de políticas educativas e comerciais brasileiras, estabelecidas com os países do Mercosul, formados por Argentina, Paraguai, Uruguai e Venezuela, sendo todos, hispanofalantes. Ademais, a supremacia do espanhol pode-se compreender também em razão da existência do PEIBF - Projeto Escola Intercultural Bilíngue de Fronteira.

O surgimento do programa se deu da necessidade e do interesse do Brasil em estreitar laços de interculturalidade com os países vizinhos que possuem cidades que fazem fronteira com o Brasil. Buscando mudar de forma radical as relações entre o Brasil e a Argentina, os documentos do MEC ressaltam que o programa se propunha então a desenvolver uma cultura de paz, colaboração interfronteiriça através da construção de uma cidadania regional, intercultural e bilíngue (ARGENTINA; BRASIL, 2008).

O PEIBF foi incentivado pelo Setor Educacional do Mercosul - SEM, que difundiu a ideia da necessidade da expansão do aprendizado "do português e do espanhol por meio dos sistemas educacionais formais e não formais" (ARGENTINA; BRASIL, 2008, s/p). O interesse do Mercosul em disseminar o conhecimento das duas línguas se deu em 1991 com a implantação do Tratado de Assunção pelos países membros do Mercosul, que através de seu artigo 23, declarou o português e o espanhol como as línguas oficiais do Mercosul.

Figura 1 - Relação das escolas participantes do PEIBF

\begin{tabular}{|l|l|}
\hline No Brasil & Em outros países \\
\hline Dionísio Cerqueira (SC) - 1 escola & Bernardo Irigoyen (Argentina) - 1 \\
\hline Foz do Iguaçu (PR) - 1 escola & Puerto Iguazu (Argentina) - 1 \\
\hline Uruguaiana (RS) - 1 escola & Paso de Los Libres (Argentina) - 1 \\
\hline São Borja (RS) - 2 escolas & Santo Tomé (Argentina) - 2 \\
\hline Itaqui (RS) - 1 escola & Alvear (Argentina) - 1 \\
\hline Itaqui - 1 escola & La Cruz (Argentina) - 1 \\
\hline Chuí (RS) - 1 escola & Chuy (Uruguai) - 1 \\
\hline Jaguarão (RS) - 2 escolas & Rio Branco (Uruguai) - 2 \\
\hline Ponta Porã (MS) - 1 escola & Pedro Juan Caballero (Paraguai) - 1 \\
\hline Pacaraima (RR) - 2 escolas & Santa Elena de Uiarén (Venezuela) 2 \\
\hline Total - 13 escolas no Brasil & Total - 13 escolas nos 4 países \\
\hline
\end{tabular}

Fonte: Brasil (2016) 
Conforme podemos averiguar com a Figura 1, as escolas brasileiras de fronteira em muito colaboram para o desenvolvimento de pesquisas interessadas em compreender em que contextos tais práticas bilíngues estão se desenvolvendo.

A Figura 1 apresenta primeiramente o município de Dionísio Cerqueira/SC, cujos limites fronteiriços se estabelecem com a cidade de Bernardo Irigoyen/ARG, que aparecem nos trabalhos de Pereira (2014) e Sagaz (2013).

A cidade de Foz do Iguaçu, conhecida por sua tríplice fronteira entre Paraguai, Brasil e Argentina, apresenta, conforme os dados do governo federal, parceria com a escola de Puerto Iguazu/ARG. Novamente, duas pesquisas aqui relacionadas (FLORES, 2011; OLIVEIRA, 2011) se inseriram no contexto de fronteira da cidade paranaense para discutir as relações fronteiriças entre a cidade argentina e a brasileira e o modelo de escola intercultural proposto pelo Ministério da Educação.

Na perspectiva do MEC, compreende-se, então, que nesse contexto, a educação para as escolas de região de fronteira deve implicar "o conhecimento e a valorização das culturas envolvidas, tendo por base práticas de interculturalidade" (ARGENTINA; BRASIL, 2008 grifo do autor).

Outras pesquisas buscaram as escolas do estado do Rio Grande do Sul, região que conta com o maior número de escolas vinculadas ao PEIBF. Enquanto a pesquisa de Braz (2010) insere-se na pequena cidade de Pacaraima/RR fronteira com Santa Elena de Uiarén/VEM, dois trabalhos foram realizados em escolas do programa de Jaguarão/RS (GONÇALVES, 2013; COUTO, 2013) relacionando as escolas do contexto brasileiro à fronteira uruguaia. Entretanto, duas pesquisas inseridas no contexto do município de Santana do Livramento/RS (CITOLIN, 2013; PREUSS, 2011), fronteira com Uruguai, encontram-se em um contexto de fronteira, mas distante das práticas do PEIBF que ainda não se estabeleceram na rede municipal.

Nobre (2011) e Vilela (2013) acrescentam com suas revisões bibliográficas questões relacionadas desde o surgimento das línguas estrangeiras no contexto brasileiro devido a seus contatos fronteiriços (NOBRE, 2011) até a influência da língua dos países vizinhos nas poesias e produções artísticas brasileiras (VILELA, 2013).

Através destas pesquisas, pudemos observar relações de poder estabelecidas entre as línguas e o contexto social onde os projetos de educação bilíngue estão presentes. Debatendo a relação entre legislações e a implementação de projetos, alguns autores das teses e dissertações atentam para o desamparo, na prática, apesar de existir um conhecido respaldo legal. Para isso, destacamos alguns trabalhos que exemplificam discussões recorrentes trazidos nas análises das pesquisas. 
Quadro 2 - Pesquisas selecionadas para discutir o contexto sócio-histórico de fronteira

\begin{tabular}{|l|l|c|c|}
\hline \multicolumn{1}{|c|}{ Autor } & \multicolumn{1}{|c|}{ Título } & Ano & Tipo de trabalho \\
\hline BRAZ & $\begin{array}{l}\text { Línguas e Identidades em Contexto de Fronteira } \\
\text { Brasil / Venezuela }\end{array}$ & 2010 & Dissertação \\
\hline CITOLIN & $\begin{array}{l}\text { Eu falo, tu hablas, vos hablás, nós ensinamos e } \\
\text { aprendemos juntos: aulas de línguas em cursos } \\
\text { binacionais }\end{array}$ & 2013 & Tese \\
\hline PEREIRA & $\begin{array}{l}\text { Programa de escolas interculturais bilíngues de } \\
\text { fronteira: integração e identidade fronteiriça }\end{array}$ & 2014 & Dissertação \\
\hline
\end{tabular}

Fonte: Elaborado pelas pesquisadoras.

Pereira (2014) destaca em sua pesquisa, primeiramente, o desafio de romper com as barreiras culturais que estigmatizam a língua e que afastam as línguas tidas como estrangeiras do espaço de enunciação.

[Excerto 01] Na escola a língua aceita é aquela do Estado-nação, a língua materna, a língua oficial, essa é a língua de ensino e aprendizagem, as outras, são línguas estrangeiras, línguas de outro Estado-nação, que possuem outro espaço de enunciação. Com o PEIBF esta situação comunicativa transformase, agora a língua estrangeira passa a ser aceita como uma língua de comunicação, chamada de segunda língua, a qual pode servir também como língua de ensino e aprendizagem, já que em um ensino bilíngue não se ensina a outra língua, mas se ensina na outra língua (PEREIRA, 2014, p. 118 - grifo nosso).

A autora destaca no trecho acima que "na escola a língua aceita é aquela do Estadonação", fazendo assim uma referência direta às relações de poder impregnadas não só na classificação de línguas minoritárias e majoritárias, mas que envolvem conceitos como língua materna, língua oficial e língua estrangeira. As diferentes relações com a língua e formas de comunicação "implica[m] conflitos, relações de dominação e de resistência, adaptação ou resistência à hierarquia, utilização da língua pela classe dominante para reforçar seu poder etc." (BAKHTIN, 1992, p. 9).

O desafio do PEIBF é aproximar as línguas oficiais de Estados-nações vizinhos, uma vez que, para os sujeitos que moram nesses contextos de fronteira, a distância dos espaços de enunciação e da cultura dos dois países se torna reduzida, influenciada e reconstruída através do contato entre os dois países e seus respectivos povos. Hoje, o PEIBF conta com 13 escolas em quatro países, sendo eles Argentina, Paraguai, Uruguai e Venezuela. Cabe novamente destacar, que todos hispanofalantes, conforme podemos ver na figura 1, anteriormente apresentada (BRASIL, 2008).

Pereira (2014) aponta que "agora a língua estrangeira passa a ser aceita como uma língua de comunicação" (Excerto 1), visto que essa língua passa a ser vista como um espaço de 
construção de uma nova situação comunicativa, em que a soberania dos Estados-nações passa a compartilhar o espaço de enunciação do Estado-vizinho, criando oportunidades para que essa segunda língua se torne também língua de ensino e aprendizagem.

Oportunizar a aprendizagem do ensino de uma segunda língua, ou língua adicional ${ }^{6}$, como instrumento de ensino e aprendizagem, possibilita não só o aprendizado do segundo idioma, mas o aprendizado no segundo idioma, característica do ensino bilíngue, também destacado pela autora (Excerto 1) “já que em um ensino bilíngue não se ensina a outra língua, mas se ensina na outra língua".

A proposta principal do PEIBF é a realização de um planejamento por professores dos países membros do programa que através de projetos de aprendizagem decidem o que deverá ser aplicado. Portanto, a intenção do programa não é o ensino de língua estrangeira, tal como ocorre nas demais escolas onde há o ensino de espanhol como segunda língua, mas do ensino na língua adicional (MEC, 2008 - grifo nosso). Ao proporcionar o ensino na língua, entendese mais do que o ensino de palavras e estruturas gramaticais, compreende-se como o ensino de outras disciplinas naquele idioma promovendo, assim, um ambiente de bilinguismo e interculturalidade para os alunos.

Pereira (2014) e outros autores em suas pesquisas atentam para detalhes do programa que desaprovam e que carecem de uma maior reflexão:

[Excerto 02] Ao se implantar o PEIBF, as escolas ficam desamparadas legalmente, já que o ensino bilíngue português-espanhol não está previsto no Sistema Educacional Brasileiro, o qual vê o idioma espanhol (castelhano para os argentinos) como uma língua estrangeira (PEREIRA, 2014, p. 102).

[Excerto 03] Apesar de se constituir em um ambiente bilíngue, onde grande parte dos estudantes não são falantes nativos de português e a língua estrangeira moderna, o espanhol em sua variedade venezuelana, ser a língua materna de muitos alunos, a escola de Pacaraima, tal qual qualquer outra instituição de ensino do estado de Roraima, prevê na sua estrutura organizacional curricular, o português como língua materna e o espanhol - em sua variedade peninsular - como língua estrangeira, esquecendo-se de seus tantos alunos falantes nativos de uma variedade latino-americana do espanhol. [...]. As evidências parecem indicar que a língua estrangeira à qual a escola atribui prestígio e legitimidade e que compõe a matriz curricular, não é a mesma língua materna do alunado que ela abriga: o que está posto no currículo parece não ter relação alguma com o contexto tão peculiar da instituição escolar (BRAZ, 2010, p. 5 - grifo nosso).

${ }^{6}$ Trabalhamos com o conceito de língua adicional a partir dos trabalhos de Leffa e Irala (2014), uma vez que "O uso do termo 'adicional' traz vantagens porque não há necessidade de se discriminar o contexto geográfico (língua do país vizinho, língua franca ou internacional) ou mesmo as características individuais do aluno (segunda ou terceira língua)", 
[Excerto 04] É importante destacar que, frequentemente, algumas políticas linguísticas e aquelas que orientam sistemas educacionais são elaboradas longe da fronteira, por quem não a vive (CITOLIN, 2013, p. 178 - grifo nosso).

Pereira (2014), utilizando a legislação como base, atenta para o desamparo das escolas integrantes do programa, para isso, a autora resgata a Lei de Diretrizes e Bases - Lei n 9394/96, que em seu artigo $5^{\circ}$, aborda que " $\mathrm{Na}$ parte diversificada do currículo será incluído, obrigatoriamente, a partir da quinta série, o ensino de pelo menos uma língua estrangeira moderna, [...]" (BRASIL, 1996 - grifo nosso). Na Constituição Federal Brasileira de 1988, Pereira, (2014) também encontra dificuldades em encontrar respaldo para o ensino bilíngue, uma vez que no Capítulo III, artigo 210 da Constituição apresenta que: "O ensino fundamental regular será ministrado em língua portuguesa, assegurada às comunidades indígenas também a utilização de suas línguas maternas e processos próprios de aprendizagem” (BRASIL, 1996). O documento deixa claro que o ensino de língua portuguesa será realizado prioritariamente em português, salvaguardando aos povos de origem indígena o direito de realizar o ensino em suas línguas maternas, não excluindo, no entanto, o aprendizado em português, apenas o relocando como segunda língua.

Conforme apresentado no capítulo teórico, reforçamos na voz de Spinassé (2006) como diferença essencial entre língua estrangeira e segunda língua ou língua adicional, que a primeira não é fundamental para a integração de um sujeito dentro do contexto social onde vive ao passo que a SL executa um papel essencial no processo de socialização desses indivíduos dentro da sociedade.

Em consonância com a crítica de Pereira (2014), Braz (2010) traz em seu trabalho que “Apesar de se constituir em um ambiente bilíngue" (Excerto 3), com sujeitos que transitam entre as culturas e espaços enunciativos dos dois países e nos dois idiomas, a prática nem sempre é condizente com o proposto pelo Programa. Utilizando a escola de Pacaraima/RR como exemplo, Braz (2010) destaca que a escola participante do programa "prevê na sua estrutura organizacional curricular, o português como língua materna e o espanhol - em sua variedade peninsular - como língua estrangeira" não necessariamente respeitando a realidade sociocultural dos indivíduos que ali habitam e que entre os dois idiomas transitam. Ao inserirse em uma escola brasileira, presume-se que a língua materna do aluno será o português e que o espanhol (ou castelhano, guarani, etc.) será a segunda língua. O tratamento do próprio espanhol como língua estrangeira pressupõe a adoção da variedade padrão da língua espanhola instituída pelo currículo escolar do sistema educacional brasileiro, através da Lei de Diretrizes 
e Bases n 9394/96 e não as variações regionais possíveis e oriundas das diferentes configurações socioculturais de cada região fronteiriça.

Neste sentido, relacionamos a crítica que Braz (2010) faz ao expressar que "o que está posto no currículo parece não ter relação alguma com o contexto tão peculiar da instituição escolar" (Excerto 3) com o excerto selecionado de Citolin (2013), quando a autora defende que "algumas políticas linguísticas e aquelas que orientam sistemas educacionais são elaboradas longe da fronteira, por quem não a vive" (Excerto 4). Ao abordar que as políticas linguísticas e educacionais são construídas em um ambiente distante do ambiente onde elas são vividas, Citolin (2013) valoriza as singularidades dos contextos sócio-históricos que influenciam não apenas a consolidação da cultura e da língua, mas que fazem parte da constituição da identidade dos sujeitos. Entretanto, ressaltamos, que "a escola, sozinha, não consegue infelizmente, reverter tendências sociolinguísticas" (MAHER, 2006, p. 106), e que tais mudanças decorrem de uma transformação coletiva.

Nossos dados apontam que as línguas de fronteira pesquisadas se limitam ao espanhol peninsular, desconsiderando o panorama histórico e cultural que compõem as diferentes fronteiras brasileiras. Os diferentes países que compõem as divisas do Brasil estabelecem geograficamente uma mesma relação com o país, que dentro do campo cultural e político não aparecem representadas da mesma forma.

As pesquisas realizadas apontam que o interesse pela compreensão das línguas de fronteira e pela cultura que transita neste ambiente são originários da proximidade geográfica do pesquisador e da instituição com este ambiente. Entretanto, estas pesquisas encontram-se em regiões de fronteiras onde há maior domínio político-comercial com os Estados vizinhos. As fronteiras do nordeste brasileiro e de boa parte da região norte, pouco atuam neste campo da educação bilíngue e do bilinguismo. Podemos destacar também que, apesar das demais regiões encontrarem campo de pesquisa relacionados ao bilinguismo e à educação bilíngue de fronteira, estas pesquisas demonstram sua preocupação com a falta de proximidade entre a realidade das propostas bilíngues e a realidade dos sujeitos que nestas regiões vivem.

\section{Considerações finais}

Buscando compreender as diferentes concepções, foi possível observar que a diversidade de autores nos aportes teóricos nem sempre esteve atrelada às concepções dos pesquisadores das teses, dissertações e artigos. Algumas das fragilidades apontadas pelos 
autores das pesquisas aqui analisadas indicam: (i) a descontinuidade de políticas linguísticas e a falta de educação bilíngue, (ii) a necessidade de valorização e respeito à diversidade cultural e linguística, (iii) o pouco reconhecimento das diferenças entre os próprios grupos minoritários e (iv) a continuidade de práticas homogeneizantes.

A pluralidade das pesquisas e dos diferentes contextos demonstrou também que as teses, dissertações e artigos retratam contextos muito diferentes, mesmo na existência de uma mesma língua, uma mesma região ou amparadas pelo mesmo projeto, como no caso do PEIBF. Entretanto, as pesquisas apontam a necessidade de se discutir ainda mais esses mesmos contextos e projetos já existentes.

Nossa leitura dos dados indica que ainda ocorrem práticas descontextualizadas ou elaboradas de forma a não valorizar a cultura e língua local, uma vez que nem sempre a língua que o aluno traz para a sala de aula é valorizada, ou ainda o contexto sócio-histórico. $\mathrm{Na}$ Declaração Universal dos Direitos Linguísticos (1996), firmada em Barcelona, estabeleceu-se que todos os povos possuem direito a expressar e promover suas culturas, línguas e diferentes formas de organização. Para isso, elas possuem o direito de dotarem-se de políticas públicas e práticas educacionais que as resguardem.

As pesquisas ainda apontam a necessidade de desenvolver políticas linguísticas e sociais que reforcem os direitos dessas minorias, o acesso, o direito e o reconhecimento de suas culturas e línguas, que deveriam também ser ensinadas e fortalecidas dentro do ambiente escolar. O ambiente escolar onde algumas dessas línguas são ensinadas e fortalecidas é apenas uma parte da vida desses sujeitos bilíngues, que não se limita as paredes da escola, mas que continua e existe além destes. As práticas situadas favorecem o uso de línguas e costumes que estes indivíduos já utilizam em seus contextos familiares e sociais também no meio escolar.

\section{REFERÊNCIAS}

ALVAREZ, I. M. J. Falar apaisanado: Uma forma de designar as línguas na fronteira. 2009. 83p. Dissertação (mestrado) - Centro de Artes e Letras. Universidade Federal de Santa Maria, Santa Maria.

BAKHTIN, M. Marxismo e Filosofia da Linguagem. São Paulo: Hucitec, 1992.

BORTONI-RICARDO, S. M. Problemas de comunicação interdialetal. Tempo Brasileiro, Rio de Janeiro, v. 9, n. 78, p. 9-32, 1984.

BRASIL. Ministério da Educação. ARGENTINA. Ministerio de Educación, Ciencia y Tecnología. Escolas de Fronteira. Disponível em: 
http://portal.mec.gov.br/seb/arquivos/pdf/Escolafronteiras/doc_final.pdf. Acesso em: 07 de outubro de 2016.

BRAZ, E. de S. Línguas e identidades em contexto de Fronteira Brasil/Venezuela. 2010. 120 f. Dissertação (Mestrado) - Curso de Linguística Aplicada, Universidade Estadual de Campinas, Campinas, 2010.

BUENO, R. G. Aquisição e/ou aprendizagem: A constituição da subjetividade e identidade de uma criança falante de português brasileiro e de espanhol. 2013. 182 f. Dissertação (Mestrado) - Curso de Linguística e Língua Portuguesa, Universidade Estadual Paulista Julio de Mesquita Filho, Araraquara, 2013.

CÁCERES, G. H. O papel da experiência linguística na relação entre alcance de memória de trabalho e compreensão leitora. 2012. 141 f. Dissertação (Mestrado) - Curso de Linguística Aplicada, Universidade Federal do Rio Grande do Sul, Porto Alegre, 2012.

CARDOSO, A. C. A gente pode aprender muito com essas trocas de línguas e não ficar preso numa língua só: práticas de linguagem na introdução do ensino bilíngue em sala de aula do Ensino Médio. 2015. 169 f. Dissertação (Mestrado) - Curso de Linguística, Universidade Federal de Santa Catarina, Florianópolis, 2015.

CAVALCANTI, M. C. Estudos sobre educação bilíngue e escolarização em contextos de minorias linguísticas no Brasil. D.e.l.t.a.: Documentação de Estudos em Lingüística Teórica e Aplicada, São Paulo - Sp, v. 15, p. 385-417, 1999.

CAVALCANTI, M. C. Multilinguismo, transculturalismo e o (re)conhecimento de contextos minoritários, minoritarizados e invisibilizados. In: MAGALHÃES, Maria Cecília C.; FIDALGO, Sueli S. (orgs) Questões de Método e de Linguagem na Formação Docente. Campinas: Mercado de Letras, pp 171-185, 2011.

CÉSAR, A. L. S.; CAVALCANTI, M. C. Do singular para o multifacetado: o conceito de língua como caleidoscópio. In: CAVALCANTI, Marilda Couto; BORTONI-RICARDO, S. M. Transculturalidade, linguagem e educação. Campinas-SP: Mercado de Letras, p. 45-66, 2007.

CITOLIN, C. B. Eu falo, tu hablas, vos hablás, nós ensinamos e aprendemos juntos: Aulas de línguas em cursos binacionais. 2013. 192 f. Tese (Doutorado) - Curso de Educação, Universidade do Vale do Rio dos Sinos - Unisinos, São Leopoldo, 2013.

COUTO, R. C. do. Ambivalência e pertencimentos culturais e nacionais nos currículos das escolas bilíngues de fronteira. In: ANPED, 36., 2013, Goiânia. Anais.... Goiânia: Anped, p. 1 $-15,2013$.

FLORES, O. V. O programa escola intercultural bilíngue de fronteira: Um olhar para novas políticas linguísticas. 2011. 127 f. Dissertação (Mestrado) - Curso de Letras, Universidade Estadual do Oeste do Paraná - Unioeste, Cascavel, 2011.

GONÇALVES, D. P. O falar dos comerciantes brasileiros na fronteira de Jaguarão-Río Branco. 2013. 132 f. Dissertação (Mestrado) - Curso de Letras, Universidade Federal de Pelotas, Pelotas, 2013. 
LIMA, L. R. de. "Uma das melhores coisas dentro dessa proposta é o espanhol": As jovens situações bilíngues encontrando a maturidade na educação via pesquisa da EJA Florianópolis. 2011. 173 f. Dissertação (Mestrado) - Curso de Linguística, Universidade Federal de Santa Catarina, Florianópolis, 2011.

MAHER, T. J. M. Ser professor sendo índio: questões de lingua(gem) e identidade. 1996. 262 f. Tese (Doutorado) - Curso de Linguística, Universidade Estadual de Campinas, Campinas, 1996.

NOBRE, W. C. de A. Introdução à história das línguas gerais no Brasil: Processos distintos de formação no Período Colonial. 2011. 233 f. Dissertação (Mestrado) - Curso de Letras, Universidade Federal da Bahia, Salvador, 2011.

PEREIRA, S. M. M. da V. Programa de escolas interculturais bilíngues de fronteira: Integração e identidade fronteiriça. 2014. 149 f. Dissertação (Mestrado) - Curso de Geografia, Universidade Federal de Santa Catarina, Florianópolis, 2014.

PREUSS, E. O. Acesso lexical e produção de fala em bilíngues Português-Espanhol e Espanhol-Português. 2011. 183 f. Tese (Doutorado) - Curso de Letras, Universidade Federal do Rio Grande do Sul, Porto Alegre, 2011.

SAGAZ, M. R. P. Projeto escolas (interculturais) bilíngues de fronteira: análise de uma ação político linguística. 2013. 156 f. Dissertação (Mestrado) - Curso de Linguística, Universidade Federal de Santa Catarina, Florianópolis, 2013.

STEIN, R. de C. G. Cross-linguistic interaction in L3 production: Portuguese as a third language in a bilingual context. 2014. 94 f. Dissertação (Mestrado) - Curso de Letras, Pontifícia Universidade Católica do Rio Grande do Sul, Porto Alegre, 2014.

STURZA, E. R. Línguas de fronteira: o desconhecido território das práticas linguísticas nas fronteiras brasileiras. Cienc. Cult., vol.57, n.2, pp. 47-50, 2005.

STURZA, E. R. Línguas de fronteiras e política de línguas: história das ideias linguísticas. 2006. 159 f. Tese (Doutorado) - Curso de Linguística, Universidade Estadual de Campinas, Campinas, 2006.

VILELA, L. S. Escrevendo na língua do outro: A relação da novíssima poesia brasileira com línguas estrangeiras. 2013. 85 f. Dissertação (Mestrado) - Curso de Literatura, Cultura e Contemporaneidade, Pontifícia Universidade Católica do Rio de Janeiro, Rio de Janeiro, 2013.

WEBER, A. F. A circulação do português e do espanhol na fronteira: $O$ global e o local no espaço entre-línguas. Raído, Dourado, MS, v. 5, n. 9, p. 217-229, jan./jun. 2011. 


\section{Como referenciar este artigo}

BARBOSA, Isabela Vieira; PISETTA, Cleide Beatriz Tambosi. Políticas linguísticas e ensino de línguas minoritárias e majoritárias no Brasil: o caso do pomerano e do inglês como línguas estrangeiras. Rev. EntreLínguas, Araraquara, v. 5, n. 1, p. 162-177, jan./jun. 2019. E-ISSN: 2447-3529. DOI: 10.29051/el.v5i1.12792

Submetido em: $26 / 03 / 2018$

Aprovado em: 12/04/2019

Publicado em: 30/04/2019 